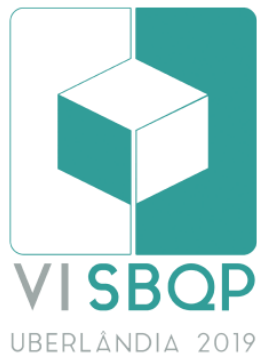

\title{
ANÁLISE DAS CONDIÇÕES DE SAÚDE E HIGIENE EM AUTOCONSTRUÇÕES EM MACEIÓ - AL
}

\author{
SANTOS, Polyanna \\ Secretaria de Estado da Infraestrutura - AL, e-mail: polyanna.omena@hotmail.com \\ OLIVEIRA, Bianca \\ UFAL, e-mail: bianca.foliveiral@gmail.com \\ OLIVEIRA, Luis \\ UNIT-AL, e-mail: arthuurmarques@gmail.com
}

\begin{abstract}
RESUMO
Este artigo é resultado das atividades de estágio na área de Arquitetura e Urbanismo em melhorias habitacionais autoconstruídas. As habitações autoconstruídas surgem da necessidade de abrigo; a falta de acompanhamento técnico na construção das moradias deixa-as vulneráveis a problemas construtivos e patologias, que podem afetar o estado de saúde dos moradores. Dessa forma, este estudo propõe avaliar as condições de saúde e higiene, após a implantação do programa de melhorias habitacionais, com o objetivo de verificar os resultados relacionados à otimização das condições ambientais e qualidade de vida dos moradores, baseado na Avaliação Pós-Ocupação, seguindo os parâmetros recomendados pela NBR 15575 (ABNT, 2013). Verificou-se que a condição atual de Saúde e Higiene das edificações, traz um maior conforto e qualidade nas habitações, mesmo não atendendo todos os requisitos da norma. Com o resultado da análise dos parâmetros é possivel concluir que a qualidade de vida dos moradores melhorou, porém, o programa de melhorias deve se aprimorar, para atender todos os quesitos referente a Saúde e Higiene da norma, uma vez que a salubridade dos ambientes é essencial.
\end{abstract}

Palavras-chave: Autoconstrução, Desempenho, Salubridade.

\begin{abstract}
The article is the result of architecture and urbanism internship in housing improvement in selfconstruction. The self-built housing arises from the necessity to shelter, the lack of technical support in the building makes them vulnerable to promote constructive problems and pathologies that can affect the health conditions of the residents. This study aimed to evaluate the health, and hygiene conditions after the program of housing improvements to verify the results of the promoted environmental conditions and quality of life of the residents, based on Post-Occupancy Evaluation followed the parameters recommended by Standard NBR 15575. (ABNT, 2013). It was found that the current condition of health and hygiene provides comfort and quality within housing, although do not cover all the requirements of the standard. The resulting for analysis indicates that the quality of life for residents improved, however, the improvement program needs to bring results for all requirements related to the health and hygiene standard, since that performance improvement of the health environment is essential.
\end{abstract}

Keywords: Self-construction, Performance, Health.

SANTOS, P.; OLIVEIRA, B.; OLIVEIRA, L. Análise das condições de saúde e higiene em autoconstruções em Maceió-AL. In: SIMPÓSIO BRASILEIRO DE QUALIDADE DO PROJETO NO AMBIENTE CONSTRUÍDO, 6., 2019, Uberlândia. Anais... Uberlândia: PPGAU/FAUeD/UFU, 2019. p. 918-929. DOI https://doi.org/10.14393/sbqp19085. 


\section{INTRODUÇÃO}

A dificuldade de acesso à terra e a habitação no Brasil é resultado de problemas históricos de cunho social, econômico e ambiental. As ocupações irregulares em áreas de fragilidade ambiental, loteamentos ilegais e favelas, oferecem riscos e insegurança aos moradores. Em Maceió, as áreas de preservação ambiental, conhecidas como grotas, são uma das principais alternativas utilizadas pelas famílias de baixa renda, para construir suas moradias.

Desde 2017, o Governo de Alagoas através do Programa Vida Nova nas Grotas, implantou uma ação de melhoria em habitações precárias nas grotas de Maceió, promovendo a inclusão social (SANTOS; SARMENTO, 2018).

Este artigo realiza o estudo das condições de saúde e higiene de habitações autoconstruídas que receberam melhorias habitacionais pelo programa estadual na Grota da Macaxeira em Maceió, Alagoas, de acordo com a norma de desempenho em edificações habitacionais - NBR 15575 (ABNT, 2013).

\section{MÉTODO}

O método de pesquisa é baseado em Avaliação Pós-Ocupação (ONO, et. al, 2018), com foco na saúde e higiene das habitações, de acordo com a NBR 15575 (ABNT, 2013). A amostra selecionada foi de 10 casas autoconstruídas na Grota da Macaxeira, Maceió - AL. O método de pesquisa dividiu-se em:

- Observação direta - coleta de dados físicos por meio de observação direta, registros fotográfico e dimensional;

- Análise técnica-construtiva das habitações - aplicação de checklisł para verificação dos critérios da NBR 15575 (ABNT, 2013);

- Avaliação da Satisfação do Usuário - coleta de dados junto aos usuários por meio de entrevistas informais e aplicação de questionário de satisfação, com respostas de múltipla escolha (escala Likert de 5 pontos, sendo 0 insatisfatório, 1 - pouco satisfatório, 2 - indiferente, 3 - satisfatório, 4 - muito satisfatório) (VOORDT; WEGEN, 2005).

\section{PARÂMETROS DE SAÚDE, HIGIENE E QUALIDADE DO AR (ABNT, 2013)}

A NBR 15575 (ABNT, 2013) determina que a construção habitacional deve prover condições adequadas de salubridade aos seus usuários, dificultando o acesso de insetos e roedores, e outros agentes agressores, recomendando como referência complementar o Código Sanitário do Estado de São Paulo (GOVERNO DE SÃO PAULO, 1998). Os critérios recomendados são:

1. Executar a construção com materiais que não favoreçam a retenção de umidade e a proliferação de fungos, algas, bactérias etc.;

2. Em coberturas, fachadas e janelas deve haver estanqueidade a poeiras e aerodispersóides, de forma que sua concentração não exceda aquela verificada no ambiente externo;

3. Em ambientes internos não devem haver umidade anormal que favoreça $\circ$ desenvolvimento de fungos e a ocorrência de doenças bronco respiratórias; 
4. Em coberturas, pisos externos e outros, não propiciar acúmulo de água que favoreçam o desenvolvimento de larvas, moscas, mosquito da dengue ou outros;

5. Em pisos, paredes, áticos de coberturas e outros elementos da construção não deve haver frestas, ou nichos, que facilitem infestação por insetos, aves e roedores;

6. Em áreas molhadas da construção devem haver pisos laváveis, com caimentos voltados na direção de ralos ou para o ambiente externo;

7. Em pisos laváveis, peças sanitárias, tampos de pias de cozinha ou banheiros, tanques de lavar roupa e outros, não deve haver poros ou frestas onde possam desenvolver germes ou bactérias.

\section{MELHORIAS HABITACIONAIS DO PROGRAMA VIDA NOVA NAS GROTAS}

O programa estadual do Governo de Alagoas, Vida Nova nas Grotas, trabalha em 100 grotas de Maceió, provendo melhorias na mobilidade urbana e melhorias construtivas nas habitações. As ações do programa, voltadas a intervenções em habitações oriundas de autoconstrução, devem proporcionar:

1. Melhorias nas coberturas - substituição de madeiramento e de telhas danificadas, complemento de elementos de madeiramento: rufos, algerozes e calhas;

2. Melhorias nos banheiros - aplicação, ou substituição, de bacias sanitárias, pias, chuveiros, revestimento e pisos cerâmicos, assentamento de portas e colocação de pré-moldados vazados para ventilação e iluminação naturais;

3. Melhorias nas cozinhas - aplicação, ou substituição, de revestimentos cerâmicos e pisos, assentamento de pia, torneira, portas e pré-moldados vazados para ventilação e iluminação naturais.

4. Melhoria nos pisos - aplicação de piso cimentício liso;

5. Melhoria nos revestimentos de paredes - aplicação de reboco.

O programa Vida Nova nas Grotas realizou visitas in loco, cadastrando famílias e identificando edificações em situações de maior precariedade, elaborando assim uma estratégia de intervenção. Para cada habitação o programa destinou em média 5 mil reais.

\section{CARACTERIZAÇÃO DA COMUNIDADE}

As Grotas se situam no planalto e são calhas de drenagem natural em demanda aos rios e riachos que deságuam na lagoa ou no mar (LIMA, 2009).

Para caracterizar a Grota da Macaxeira foi necessário descrever os aspectos ambientais, socioeconômicos e habitacionais, descritos a seguir.

\subsection{Tabelas, Aspectos ambientais}

A Grota do Macaxeira fica situada no bairro da Chã da Jaqueira, em Maceió, Alagoas. Sua população é de 777 habitantes (IBGE, 2010). Em 2016, esta comunidade passou por um processo de reurbanização (Figura 1), realizado pelo Governo do Estado de Alagoas e com parceria da ONU-Habitat, por meio do 
programa Vida Nova nas Grotas. O lugar antes era inóspito e sem condições de mobilidade. As ações efetuadas compreenderam a otimização da mobilidade e dos espaços de convivência.
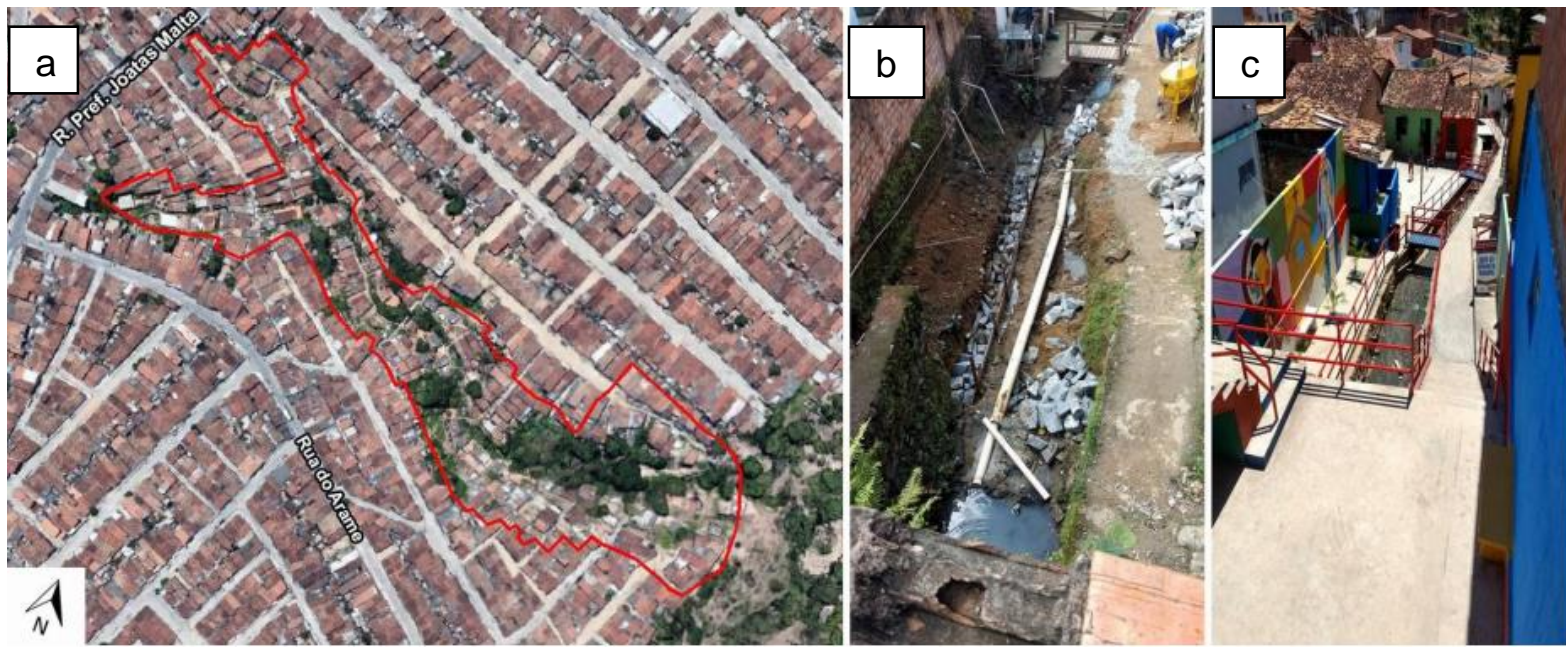

Figura 1 - Grota da Macaxeira - Localização geográfica da Grota da Macaxeira (a), Situação original (b), Situação atual (c) Fonte: SEINFRA (2018) e acervo dos autores (2018)

\subsection{Aspectos socioeconômicos}

A estrutura familiar encontrada na grota, em sua maioria, é composta por 3 pessoas: esposa e marido e um filho (22\%). Em outros $21 \%$ das famílias, a estrutura é de 4 moradores (pai, mãe e dois filhos). 18\% das famílias são compostas por 2 pessoas: esposa e marido. $15 \%$ das famílias contêm 5 pessoas. $9 \%$ das famílias tem somente 1 pessoa. 7\% das famílias é composta por 6 pessoas. Em 3\% das famílias a estrutura é composta por 10 pessoas e 7 pessoas. E $2 \%$ das famílias é composta por 8 pessoas (Gráfico 1) (IBGE, 2010). Com relação à renda familiar, observou-se que muitos vivem de benefícios sociais, como aposentadoria ou bolsa família. A renda mensal familiar é de no máximo um salário mínimo (atualmente $R \$ 998,00$ novecentos e noventa e oito reais).

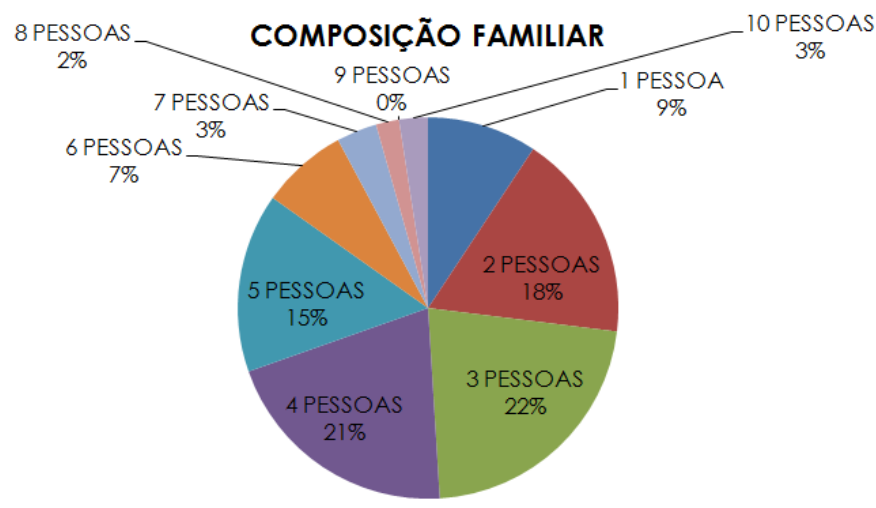

Gráfico 1 - Composição familiar do moradores da Grota da Macaxeira Fonte: Autores (2019)

\subsection{Aspectos habitacionais}

As moradias encontradas nas grotas são casas autoconstruídas pela própria comunidade e por algumas vezes com materiais improvisados - pedaços de 
madeira, mais de um tipo de material para construção de alvenaria, portas inadequadas, fiação elétrica exposta, etc.

A predominância é de casas geminadas, sem recuos e estreitas, construídas em alvenaria de tijolos cerâmicos, com cobertura em telhas de fibrocimento e piso cimentício. Quanto à tipologia construtiva, verifica-se que na maioria dos casos as casas são térreas ou de dois pavimentos. As poucas aberturas para ventilação natural, estão posicionadas na fachada principal.

\section{DISCUSSÃO DOS RESULTADOS}

Para cada habitação analisada, foram descritas as melhorias realizadas pelo programa governamental, a análise técnica e o parecer do morador, a seguir:

\section{Casa A:}

Melhorias realizadas: Serviços na cobertura, troca do madeiramento e telhas desgastadas, eliminando a umidade; melhorias no banheiro: aplicação de piso e revestimento cerâmico; melhorias na cozinha: aplicação de revestimento cerâmico nas áreas molhadas da cozinha; e serviços complementares: reboco nas paredes e revestimento cerâmico na área molhada da área de serviço (Figura 2).

Análise Técnica: $O$ madeiramento era inadequado e as telhas tinham fissuras que ocasionava pingueiras e infiltração em partes da cobertura, deixando as paredes molhadas. A alvenaria exposta (sem reboco e/ou revestimento) era um ambiente para abrigo de insetos, consolidação da umidade e consequentemente surgimento de microrganismo. E o piso do banheiro era cimentício, tornando-o insalubre.

Percepção do morador: A moradora disse está satisfeita, a mesma possui asma e relatou que depois das melhorias, suas crises asmáticas reduziram e que a higienização dos ambientes ficaram mais fáceis.
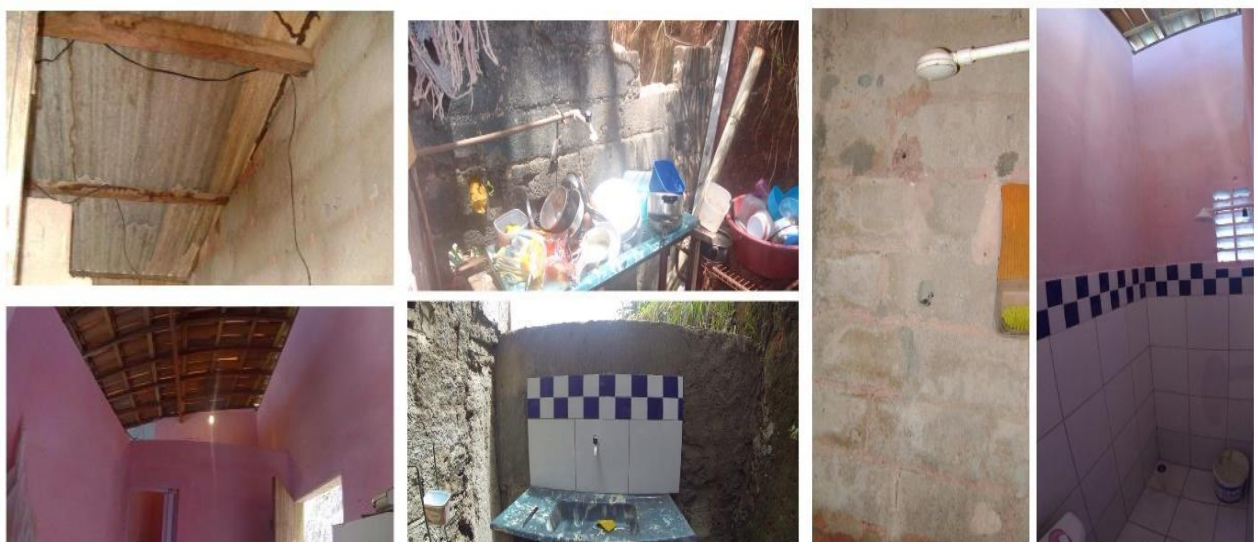

Figura 2 - Melhorias realizadas na casa A -

Fonte: SEINFRA (2018)

Casa B:

Melhorias realizadas: Serviços na coberta, com a substituição do madeiramento e de telhas desgastadas por novas; melhorias no banheiro: aplicação de piso revestimento cerâmico; melhorias na cozinha: aplicação de revestimento cerâmico nas áreas molhadas da cozinha; e serviços complementares: serviços de pintura na parte interna e externa da moradia, (Figura 3). 
Análise Técnica: A coberta apresentava telhas e madeiramento com necessidade de substituição, pois estavam mal conservados e possuíam aberturas entre as telhas, propiciando a entrada de chuva e poeira no interior da moradia. A falta de revestimento cerâmico proporcionava um maior acúmulo de sujeira e dificuldade de limpeza.

Percepção do morador: Foi relatado pelo morador maior satisfação em relação a higiene e a facilidade de limpeza da casa, principalmente nas áreas molhadas (cozinha e banheiro). A umidade e mofo nos ambientes foram eliminados após as melhorias.
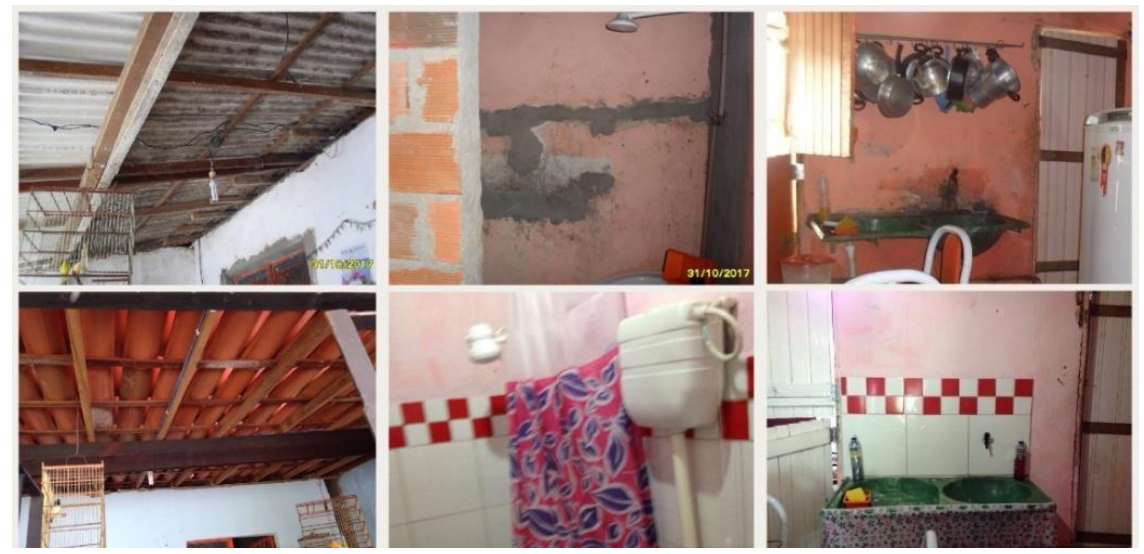

Figura 3 - Melhorias realizadas na casa B -

Fonte: SEINFRA (2018)

\section{Casa C:}

Melhorias realizadas: Substituição de parte do madeiramento e das telhas danificadas; melhorias na cozinha: aplicação do revestimento cerâmico na área molhada, permitindo melhor higienização e pintura da alvenaria (Figura 4).

Análise Técnica: Parte do madeiramento estava danificado por cupins e as telhas com rachaduras. Não havia revestimento cerâmico na cozinha. Os ambientes eram úmidos, com proliferação de fungos.

Percepção do morador: A moradora afirmou estar muito satisfeita, pois houve a eliminação da umidade na residência e redução de insetos.

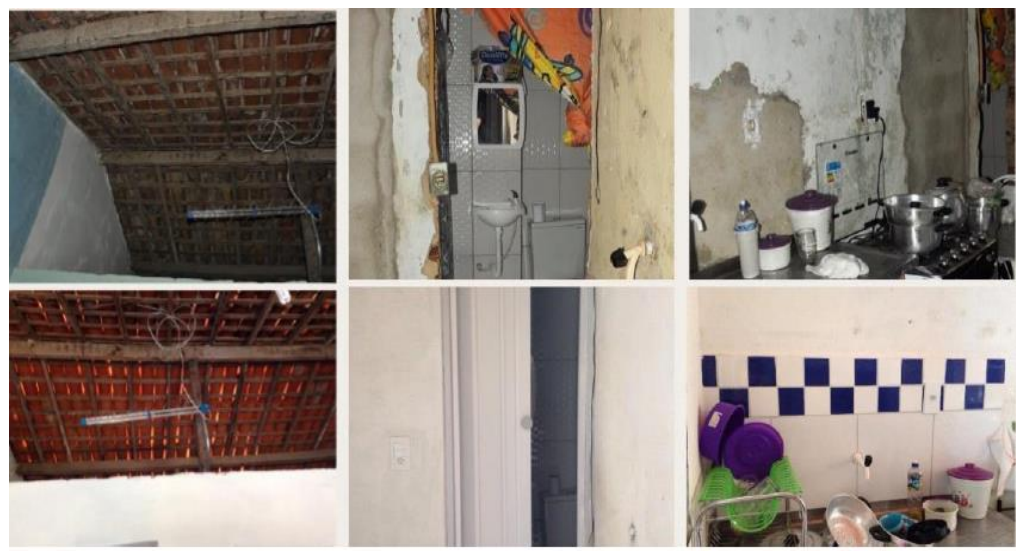

Figura 4 - Melhorias realizadas na casa $C$ -

Fonte: SEINFRA (2018) e acervo dos autores (2018) 


\section{Casa D:}

Melhorias realizadas: Serviços na cobertura, aumentando o pé-direito da residência, troca de telhas danificadas e pintura no madeiramento; melhoria no banheiro: aplicação de piso e revestimento cerâmico; melhoria na cozinha: revestimento cerâmico na área molhada da cozinha; e serviços complementares: pintura nas paredes (Figura 5).

Análise Técnica: A coberta possuía um pé-direito baixo, causando um péssimo conforto térmico no local. A troca de telhas danificadas impediu a entrada de roedores e insetos. Com a colocação do revestimento facilitou a limpeza e manutenção e dificultou a proliferação de microrganismos.

Percepção do morador: Segundo a moradora a melhoria feita pelo Programa Vida Novas Nas Grotas lhe deixou muito satisfeita com o resultado, já que a mesma não possuía condições financeiras para modificações. Gerando uma facilidade na higienização dos ambientes, deixando sua casa mais confortável.
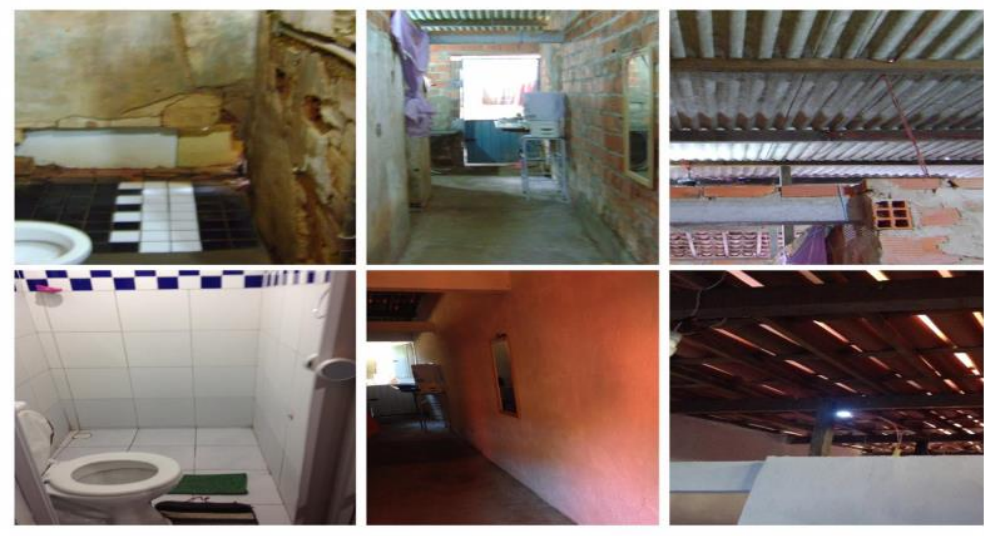

Figura 5 - Melhorias realizadas na casa D -

Fonte: SEINFRA (2018) e acervo dos autores (2019)

\section{Casa E:}

Melhorias realizadas: Substituição de telhas na coberta, organização da fiação elétrica; melhoria no banheiro: nova pia e adição de revestimento e piso cerâmico (Figura 6).
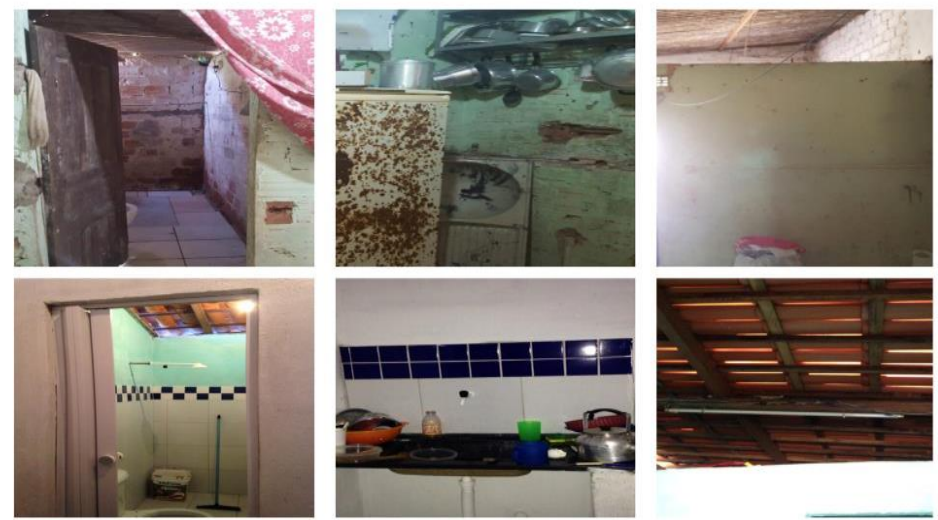

Figura 6 - Melhorias realizadas na casa E -

Fonte: SEINFRA (2018)

Análise Técnica: A casa possuía telhas com necessidade de substituição devido o desgaste decorrente do tempo, assim como a fiação elétrica desgastada e com 
fios aparentes. O banheiro não possuía revestimento cerâmico nos pisos e nem nas paredes tornando o ambiente insalubre e de difícil higienização.

Percepção do morador: A moradora relatou a melhora nas condições de saúde, que suas crises alérgicas diminuíram. A mesma observou uma redução de insetos e roedores. A higienização da residência foi otimizada, principalmente no banheiro.

\section{Casa F:}

Melhorias realizadas: Substituição da coberta, realizando a troca do madeiramento e das telhas; melhoria no banheiro: aplicação de revestimento e piso cerâmico, e pintura da parede; e serviços complementares: revestimento cerâmico na área molhada da área de serviço (Figura 7).

Análise Técnica: $O$ madeiramento se encontrava com mofo e cupim, e as telhas estavam porosas e com fissuras. O banheiro não tinha revestimento e piso cerâmico, apresentando constante umidade, além de ter sua cobertura com telhas de fibrocimento. A área molhada da área de serviço era na alvenaria, tornando-se um agente propício a proliferação de microrganismos.

Percepção do morador: A moradora informou que facilitou a higienização dos ambientes, e deixou a casa mais confortável, que está muito satisfeita com as melhorias.
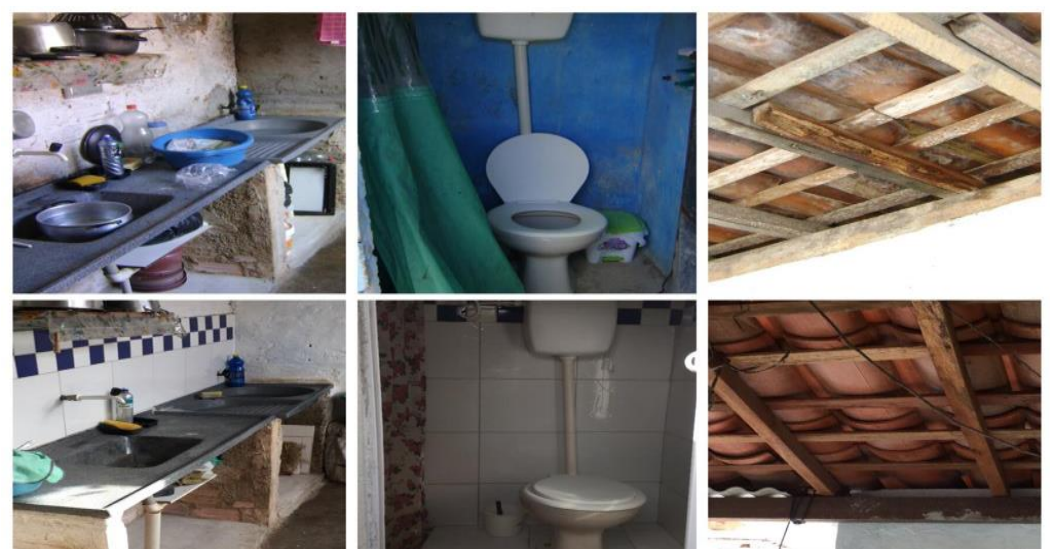

Figura 7 - Melhorias realizadas na casa F -

Fonte: SEINFRA (2018) e acervo dos autores (2019)

\section{Casa G:}

Melhorias realizadas: Troca de parte do madeiramento e das telhas; melhorias na cozinha: revestimento cerâmico na área molhada e pintura do cômodo; e serviços complementares: limpeza da calha e aplicação de revestimento cerâmico na área de serviço (Figura 8).

Análise Técnica: Parte do madeiramento estava com cupim e as telhas desgastadas e com machas de umidade; as áreas molhadas da área de serviço e da cozinha não possui revestimento cerâmico, o que permitia a desenvolvimento de microrganismos.

Percepção do morador: A moradora disse está satisfeita, que após as melhorias implantas, sua casa ficou mais fácil de limpar, tornando os ambientes mais agradáveis. 

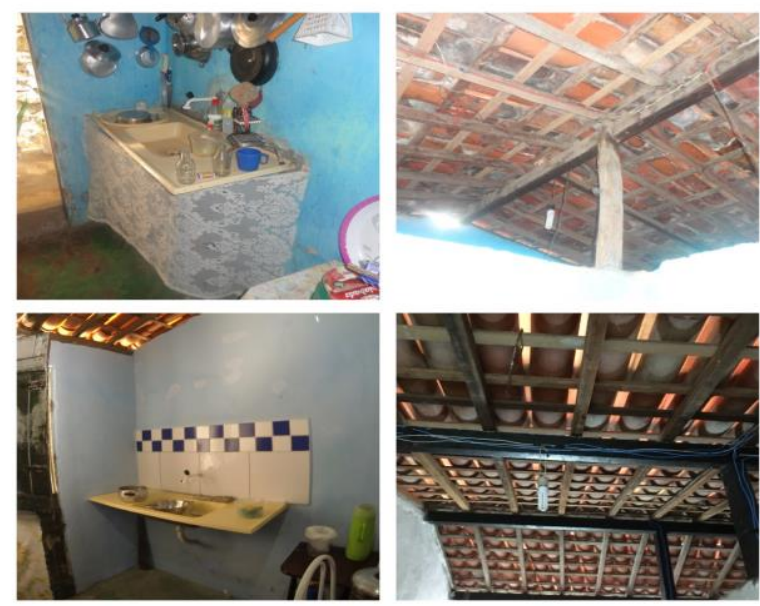

Figura 8 - Melhorias realizadas na casa $\mathbf{G}$ -

Fonte: SEINFRA (2018) e acervo dos autores (2019)

\section{Casa H:}

Melhorias realizadas: Serviços na cobertura com a troca do madeiramento e telhas desgastadas, pintura nos elementos do madeiramento, organização da fiação elétrica; melhoria no banheiro: aplicação de piso e revestimento; melhoria na cozinha: revestimento cerâmico nas áreas molhadas; e serviços complementares: reboco e pintura nas paredes, e revestimento cerâmico nas áreas molhadas da área de serviço (Figura 9).

Análise Técnica: Na coberta o madeiramento estava deteriorado devido o cupim e com telhas danificadas. Essas patologias causavam infiltrações e facilidades da entrada de roedores e insetos. No banheiro foi feita a instalação revestimento e piso cerâmico, ajudando na limpeza e evitando a entrada de roedores.

Percepção do morador: A moradora ficou muito satisfeita com as melhorias, porém gostaria de mais, como a adição do piso cerâmica em toda casa. A mesma interviu na residência após as melhorias, ela fechou um quarto que divide a residência vizinha, tirou o tanque e alguns revestimentos na área de serviço.
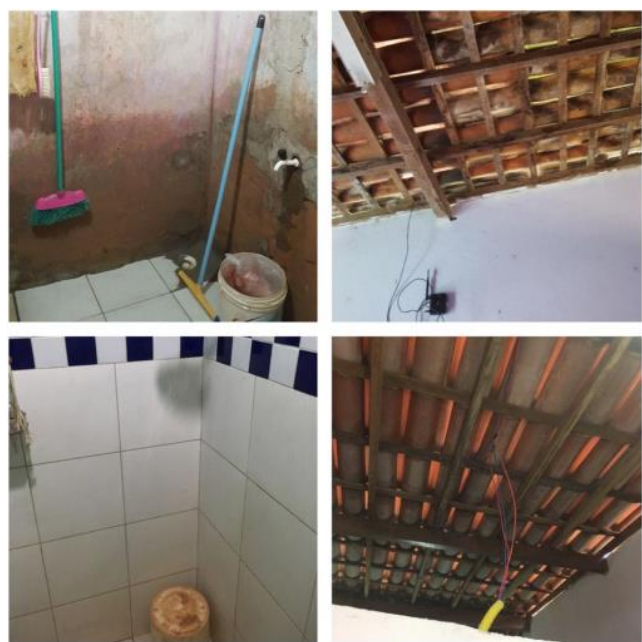

Figura 9 - Melhorias realizadas na casa $\mathrm{H}$ Fonte: SEINFRA (2018) e acervo dos autores (2019) 


\section{Casa I:}

Melhorias realizadas: Substituição do madeiramento e das telhas; e melhoria no banheiro: aplicação de revestimento cerâmico, instalação da porta, troca da pia, bacia sanitária e chuveiro (Figura 10).

Análise Técnica: A cobertura apresentava infiltração e desenvolvimento de vegetação, além de que estava desgastada e com madeiramento inadequado. As paredes do banheiro tinham sua alvenaria de tijolo cerâmico a mostra.

Percepção do morador: $O$ morador informou estar muito satisfeito, pois realizou o sonho de sua mãe antes da mesma vir a óbito; e que melhorou sua qualidade de vida.

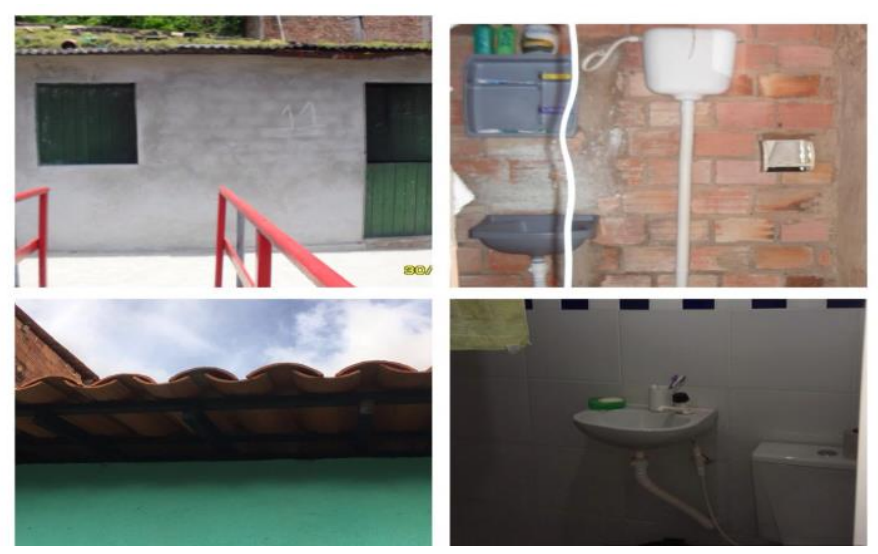

Figura 10 - Melhorias realizadas na casa I -

Fonte: SEINFRA (2018) e acervo dos autores (2019)

Casa J:

Melhorias realizadas: Serviços na cobertura, troca do madeiramento e telhas desgastadas, organização e troca da fiação; melhorias no banheiro: pintura do banheiro, substituição do vaso sanitário, chuveiro; melhorias na cozinha: aplicação de revestimento cerâmico nas áreas molhadas (Figura 11).
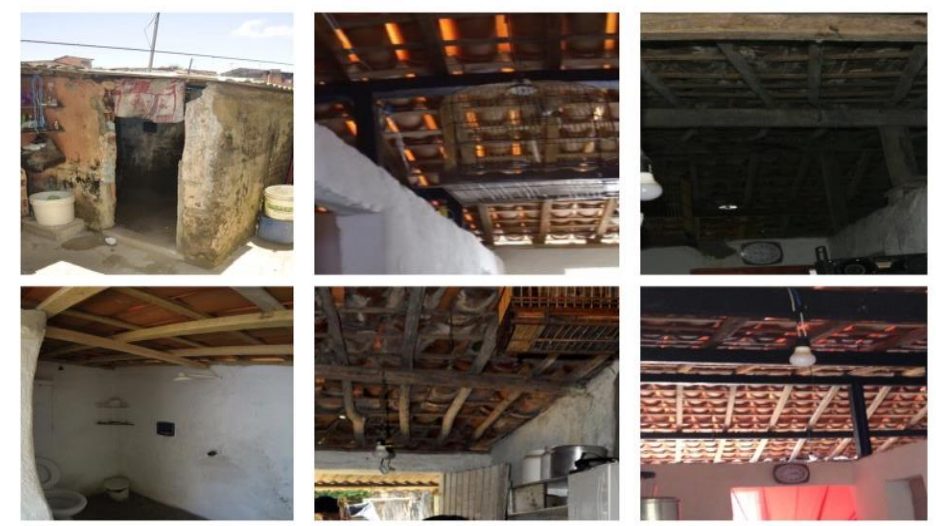

Figura 11 - Melhorias realizadas na casa J -

Fonte: SEINFRA (2018) e acervo dos autores (2019)

Análise Técnica: $O$ madeiramento era inadequado e as telhas tinham fissuras que ocasionava pingueiras e infiltração em partes da cobertura, deixando as paredes molhadas. Também entrava roedores e insetos pelas fissuras. A alvenaria exposta 
(sem reboco e/ou revestimento) era um ambiente para abrigo de insetos, consolidação da umidade e consequentemente surgimento de microrganismo.

Percepção do morador: O morador relatou que está satisfeito com as melhorias, disse que acabou com o aparecimento dos roedores e insetos. Além de facilitar a higienização e manutenção da casa.

De acordo com entrevistas realizadas, $90 \%$ dos entrevistados demonstraram satisfação com as melhorias habitacionais. Foi ressaltada nas respostas obtidas, a percepção da melhoria na qualidade de vida obtida, a redução dos riscos de contágio de doenças, pela proliferação de microrganismos ou infestação de insetos, facilitando a higienização dos ambientes e reduzindo as doenças respiratórias.

Em relação ao atendimento dos critérios - listados no item 3 - para condições adequadas de salubridade aos usuários, 3 das habitações atenderam a todos os critérios, garantindo uma mudança significativa na qualidade de vida dos usuários. 2 habitações atenderam a $85 \%$ dos itens analisados. 1 atendeu a $71 \% .2$ moradias a $42 \%$ dos critérios; e 2 a $28 \%$ (Tabela 1).

Tabela 1 - Síntese da análise dos critérios das autoconstruções após as melhorias habitacionais

\begin{tabular}{|l|c|c|c|c|c|c|c|c|c|c|}
\hline $\begin{array}{c}\text { Atende: } \\
\text { SIM/ NÃO }\end{array}$ & $\begin{array}{c}\text { Casa } \\
\text { A }\end{array}$ & $\begin{array}{c}\text { Casa } \\
\text { B }\end{array}$ & $\begin{array}{c}\text { Casa } \\
\text { C }\end{array}$ & $\begin{array}{c}\text { Casa } \\
\text { D }\end{array}$ & $\begin{array}{c}\text { Casa } \\
\mathbf{E}\end{array}$ & $\begin{array}{c}\text { Casa } \\
\mathbf{F}\end{array}$ & $\begin{array}{c}\text { Casa } \\
\mathbf{G}\end{array}$ & $\begin{array}{c}\text { Casa } \\
\mathbf{H}\end{array}$ & $\begin{array}{c}\text { Casa } \\
\mathbf{I}\end{array}$ & $\begin{array}{c}\text { Casa } \\
\mathbf{J}\end{array}$ \\
\hline Critério 1 & SIM & SIM & SIM & SIM & SIM & SIM & SIM & NÃO & SIM & NÃO \\
\hline Critério 2 & SIM & SIM & SIM & SIM & SIM & SIM & SIM & SIM & SIM & SIM \\
\hline Critério 3 & SIM & SIM & NÃO & SIM & SIM & SIM & SIM & NÃO & SIM & NÃO \\
\hline Critério 4 & SIM & NÃO & SIM & NÃO & SIM & SIM & NÃO & SIM & SIM & NÃO \\
\hline Critério 5 & SIM & NÃO & SIM & SIM & SIM & SIM & NÃO & NÃO & NÃO & NÃO \\
\hline Critério 6 & SIM & SIM & SIM & SIM & SIM & SIM & NÃO & NÃO & SIM & NÃO \\
\hline Critério 7 & SIM & SIM & SIM & SIM & SIM & SIM & NÃO & NÃO & NÃO & NÃO \\
\hline
\end{tabular}

\section{CONSIDERAÇÕES FINAIS}

A precariedade das famílias impede que eles possam efetuar reparos nas casas, notando-se a falta de manutenção da moradia, condições insalubres e de má conservação.

O Programa Vida Nova nas Grotas demonstrou ser uma boa iniciativa para amenizar as condições de precariedade das habitações, acarretando em melhores condições de morar, de manter a saúde e a segurança das famílias.

Apesar das melhorias habitacionais representam muito para os moradores e trazer para eles uma mudança na qualidade de vida significativa, é preciso que aconteça uma evolução no Programa, atentando para atender os Parâmetros de Saúde, Higiene e Qualidade do Ar (ABNT, 2013) e também os outros itens da norma, objetivando aproximar o máximo possível do Desempenho numa habitação. 


\section{REFERÊNCIAS}

ASSOCIAÇÃO BRASILEIRA DE NORMAS TÉCNICAS. NBR 15575 Edificaçōes

habitacionais: Desempenho. Rio de Janeiro: ABNT, 2013.

INSTITUTO BRASILEIRO DE GEOGRAFIA E ESTATÍ́sTICA (IBGE). Censo Brasileiro de 2010. Rio de Janeiro: IBGE, 2012.

LIMA, B. M. Áreas de proteção permanente-APPs em Maceió: do ideário conservacionista aos usos sócio-ambientais das zonas de interesse ambiental e paisagístico. 2009. 155 f. Dissertação (Mestrado em Dinâmicas do Espaço Habitado) - Universidade Federal de Alagoas, Maceió, 2009.

ONO, R.; ORNSTEIN, S. W.; VILLA, S. B.; FRANÇA, A. J. G. L. Avaliação pós- ocupação na arquitetura, no urbanismo e no design: da teoria à prática. São Paulo: Ed. Oficina de Textos, 2018.

SANTOS, P. O. C; SARMENTO, T. F. C. S. Análise da percepção dos usuários sobre melhorias construtivas realizadas em habitações precárias em Maceió, Alagoas. In: ENCONTRO NACIONAL DE TECNOLOGIA DO AMBIENTE CONSTRUÍDO, 17., 2018, FOZ do IguaçU. Anais eletrônicos... Porto Alegre: Antac, 2018.

SÃO PAULO. Lei $n^{\circ}$ 10.083, de 23 de setembro de 1998. São Paulo, SP: Secretaria da Assembleia Legislativa do Estado de São Paulo, 15 out. 1999.

VOORDT, D. J. M. van der; WEGEN, H. B. R. van. Architecture In Use: An introduction to the programming, design and evaluation of buildings. Architectural Press, 2005. 